\title{
Clinical Study \\ Response to Cardiac Resynchronization Therapy: The Muscular Metabolic Pathway
}

\author{
Jérémie Jaussaud, Pierre Blanc, Pierre Bordachar, Raymond Roudaut, and Hervé Douard \\ Division de Cardiologie Clinique, Hôpital Cardiologique, du Haut Lévêque, CHU de Bordeaux, Avenue Magellan, \\ 33600 Pessac, France \\ Correspondence should be addressed to Jérémie Jaussaud, jeremie.jaussaud@yahoo.fr
}

Received 5 October 2010; Accepted 23 November 2010

Academic Editor: Filippos Triposkiadis

Copyright ( $\odot 2011$ Jérémie Jaussaud et al. This is an open access article distributed under the Creative Commons Attribution License, which permits unrestricted use, distribution, and reproduction in any medium, provided the original work is properly cited.

\begin{abstract}
Background. Changes in peripheral muscle in heart failure lead to a shift from aerobic to early anaerobic metabolism during exercise leading to ergoreflex overactivation and exaggerated hyperventilation evaluated by the $\mathrm{VE} / \mathrm{VCO}_{2}$ slope. Methods. 50 patients (38 males, $59 \pm 12$ years) performed cardio-pulmonary exercise test with gaz exchange measurement and echocardiographic evaluation before and 6 months after CRT. Results. The peak respiratory exchange $\left(\mathrm{VCO}_{2} / \mathrm{VO}_{2}\right)$ ratio was significantly reduced from $1.16 \pm 0.14$ to $1.11 \pm 0.07(P<.05)$ and the time to the anaerobic threshold was increased from $153 \pm 82$ to $245 \pm 140$ seconds $(P=.01)$. Peak $\mathrm{VO}_{2}, \mathrm{VE} / \mathrm{VCO}_{2}$, peak circulatory power and NYHA were improved after CRT $(13 \pm 4$ to $16 \pm 5 \mathrm{ml} / \mathrm{kg} / \mathrm{min}(P<.05)$, $45 \pm 16$ to $39 \pm 13(P<.01), 1805 \pm 844$ to $2225 \pm 1171 \mathrm{mmHg} \cdot \mathrm{ml} / \mathrm{kg} / \mathrm{min}(P<.01)$ and $3 \pm 0.35$ to $1.88 \pm 0.4(P=.01)) . \mathrm{In}$ addition, left ventricular ejection fraction and end-systolic volumes were improved from $24 \pm 8$ to $29 \pm 7 \%(P<.01)$ and from $157 \pm 69$ to $122 \pm 55 \mathrm{ml}(P<.01)$. Conclusion. We suggest that CRT leads to an increase in oxidative muscular metabolism and postponed anaerobic threshold reducing exaggerated hyperventilation during exercise.
\end{abstract}

\section{Introduction}

It remains unclear how cardiac resynchronization therapy (CRT) improves symptom status in heart failure population. CRT is one of the major treatment for patients suffering from refractory heart failure (HF) despite an optimal drug regimen [1]. Huge previous trialsconfirmed improvement in both symptom status (NYHA class) and remodelling parameters (left ventricular (LV) ejection fraction, mitral regurgitation, and LV end-systolic volume) [2]. In addition, objective functional parameters are improved by CRT (peak oxygen uptake, 6-minute walking test, peak workload, exercise duration) [3]. It was well confirmed that heart failure patients present an exaggerated hyperventilationcharacterised by an increase in the slope relating the minute ventilation to carbon dioxide production $\left(\mathrm{VE} / \mathrm{VCO}_{2}\right)$ leading to early fatigue and breathlessness during the effort [4].

Physiopathological determinants of such an hyperventilation remain unclear. Nevertheless, an important cause of hyperpnea during effort is the enlargement of physiological dead space and ventilation-perfusion mismatch by alveolar hypoperfusion from hemodynamic dysfunction. Another determinant is the early cardiorespiratory reflex dysregulation. This was evidenced by increased peripheral and central chemosensitivity, impaired sympathovagal balance with sympathetic predominance, and depressed baroreflex circulation control $[5,6]$. In addition, in heart failure population, the skeletal musculature has been extensively investigated. Muscle bulk is known to be reduced, and abnormalities of muscle function, histologic features, and metabolism have all been described [7]. In particular, both reduction in capillary density and shift from slow-twitch-type 1 muscular fibres to fast-twitch-type 2 fibres were found. It leads to depressed oxidative capacity by a reduction in mitochondrial density and increases the glycogenolytic metabolism, the carbon dioxide production, and the respiratory exchange ratio at peak of the exercise $\left(\mathrm{VCO}_{2} / \mathrm{VO}_{2}\right)$ [8]. These muscular modifications are associated with an overactivation of 
the peripheral ergoreflex leading to an early hyperventilation during exercise (the "muscle hypothesis") [9].

We suggest that reduction in exaggerated hyperventilation during exercise in HF population after CRT is linked to an improvement in musculature metabolism, which results in increasing oxidative metabolism, reducing the respiratory exchange ratio at peak of the exercise, and improving the time to anaerobic threshold (AT).

\section{Methods}

Fifty consecutive refractory HF patients were enrolled in this single center investigation. All those patients matched the following criteria: indication for CRT implantation according to current indications (QRS duration $>120 \mathrm{~ms}$, LV ejection fraction $<35 \%$, NYHA symptom class II-III or IV, and optimal heart failure medical regimen) [10]. Complete echocardiographic evaluation including LV volume measurements and a cardiopulmonary exercise were realized before and 6 months after CRT implantation. Patients with history of chronic lung diseases were excluded.

2.1. Echocardiographic Measurement. Echocardiograms were loaded into a computer system (Echopac, GE), and all measurements were obtained for all patients at baseline and 6 months after implantation. Echocardiograms were analyzed by a single experienced sonographer.

Sample loops were analyzed off line on an Echopac computer workstation to obtain end-diastolic (EDV) and endsystolic LV (ESV) volumes using the methods of disks. Ejection fraction was calculated as follows: $(\mathrm{EDV}-\mathrm{ESV}) / \mathrm{EDV} \times$ $100 \%$. Mitral regurgitation was evaluated according to the European Society of Echocardiography [11].

2.2. Testing Procedure and Data Collection. A symptomlimited exercise test with ventilatory expired gas analysis using a cycle ergometer with a 10 Watts/minute protocol was performed in all patients in an air conditioned room (Ergo Card, Medisoft, Sorinnes, Belgium). Continuous standard 12 lead electrocardiograms, manual blood pressure measurements, and heart rate recordings were monitored at every stage. Data for oxygen consumption $\left(\mathrm{VO}_{2}\right)$, carbon dioxide production $\left(\mathrm{VCO}_{2}\right)$, minute ventilation $(\mathrm{VE})$, respiratory rate (RR), and work load were collected continuously throughout the exercise. Oxygen and carbon dioxide sensors were calibrated using gases with known oxygen, nitrogen, and carbon dioxide concentrations prior to each test. Ventilatory efficiency was obtained by the linear regression slope relating $\mathrm{VE}$ to $\mathrm{VCO}_{2}$ from the beginning to the peak of the effort [12]. Peak $\mathrm{VO}_{2}$ was used as an index of exercise capacity.

The peak circulatory power was measured as an evaluation of the cardiac pumping function by the product of the peak $\mathrm{VO}_{2}$ and the systolic blood pressure as described by Cohen-Solal et al. [13]. The respiratory exchange ratio (RER) was measured by the rapport between the carbon dioxide production $\left(\mathrm{VCO}_{2}\right)$ and the oxygen consumption $\left(\mathrm{VO}_{2}\right)$. The peak RER was used in this study. The anaerobic threshold was assessed using Wasserman's method. All exercises were realized after written agreements of patients.

2.3. Subgroup Analysis. the responders and the nonresponders to the CRT were characterized. The responder subgroup was defined as having a telesystolic LV volume reduction greater than $15 \%$ after CRT [14].

2.4. Statistical Analysis. Paired t tests were used to compare differences between parameters at baseline and after CRT. All statistical tests with a $P$ value of $<.05$ were considered to be significant. Continuous variables are summarized by mean \pm SD.

\section{Results}

3.1. Patients. Baseline characteristics of patients included are summarized in Table 1. Heart failure etiology was ischaemic in $46 \%$ and nonischaemic in 54\%. Patients had severely depressed LV function with a mean LV ejection fraction of $24 \pm 8 \%$. Mean NYHA symptom class was $2,98 \pm 0,35$, and mean QRS duration was $154 \pm 35 \mathrm{~ms}$. Mean values of peak $\mathrm{VO}_{2}$ and $\mathrm{VE} / \mathrm{VCO}_{2}$ slope were $13 \pm 4 \mathrm{ml} / \mathrm{kg} /$ minute and $45 \pm 16$. Mean maximal work load at peak of the exercise and the mean peak circulatory power were $78 \pm 28$ Watts and $1805 \pm 744 \mathrm{mmHg} \cdot \mathrm{ml} / \mathrm{kg} / \mathrm{min}$. Mean peak RER was $\mathrm{ml} / \mathrm{min}, 1,16 \pm 0,14$. EDV and ESV were $205 \pm 79 \mathrm{ml}$ and $157 \pm 69 \mathrm{ml}$, respectively. Mean mitral regurgitation grade was $1,49 \pm 1$.

3.2. 6-Month Followup after CRT. At 6 months, mean values of NYHA,peak $\mathrm{VO}_{2}, \mathrm{VE} / \mathrm{VCO}_{2}$ slope and RER at the peak were $1,88 \pm 0,4(P<.01), 16 \pm 5 \mathrm{ml} / \mathrm{kg} / \mathrm{min}(P<.05), 39 \pm$ $13(P<.01)$ and $1,11 \pm 0,07(P<.05)$, respectively. Mean time to anaerobic threshold was improved from $153 \pm 82$ to $245 \pm 140$ seconds $(P=.01)$. Left ventricular remodelling parameters were significantly improved. Mean values of EDV, ESV, and ejection fraction were $175 \pm 71 \mathrm{ml}(P<.01)$, $122 \pm 55 \mathrm{ml}(P<.01)$, and $31 \pm 8 \%(P<.01)$, respectively. Efficient biventricular pacing was assessed by CRT control at 6 months.

3.3. Subgroup Analysis. 23 patients ( 18 males, $61 \pm 10$ years) $(46 \%)$ were included in the nonresponder subgroup. Major HF etiology was ischaemic in 56\%, and mean QRS duration was $144 \pm 39 \mathrm{~ms}$.

In this population, NYHA symptom was improved from $2,83 \pm 0,5$ to $2 \pm 0,34(P<.01)$. Peak $\mathrm{VO}_{2}, \mathrm{Ve} / \mathrm{VCO}_{2}$ slope, RER, and RR did not change ( $13 \pm 2$ to $15 \pm 5 \mathrm{ml} / \mathrm{kg} / \mathrm{min}$, $46 \pm 10$ to $41 \pm 8,1,14 \pm 0,14$ to $1,1 \pm 0,07$, and $30 \pm 4$ to $27 \pm 4 / \mathrm{min}$, respectively; $P>.05$ ). Mean time to anaerobic threshold was not significantly increased from $183 \pm 90$ to $225 \pm 122$ seconds $(P>.05)$. No significant increase in exercise duration and peak workload was found 6 months after CRT. Rest HR was decreased from $77 \pm 16 \mathrm{bpm}$ to $73 \pm 9 \mathrm{bpm}(P>.05)$, and peak circulatory power did not change from $1733 \pm 480$ to $2021 \pm 803 \mathrm{~mm} \mathrm{Hg} \cdot \mathrm{ml} / \mathrm{kg} / \mathrm{min}$ $(P>.05)$. In this subgroup, LV tele-systolic, ejection fraction 
TABLE 1: Population characteristics before and after CRT.

\begin{tabular}{|c|c|c|c|}
\hline & Baseline & 6-month followup & $P$ \\
\hline Subjects & 50 & & \\
\hline Male & $38(76 \%)$ & & \\
\hline Female & $12(24 \%)$ & & \\
\hline Age, yrs & $59 \pm 12$ & & \\
\hline Left ventricular ejection fraction, $\%$ & $24 \pm 8$ & $29 \pm 7$ & $<.01$ \\
\hline \multicolumn{4}{|l|}{ Etiology } \\
\hline Ischaemic & $23(46 \%)$ & & \\
\hline Nonischaemic & $27(54 \%)$ & & \\
\hline $\mathrm{SBP}$ at rest, $\mathrm{mmHg}$ & $108 \pm 18$ & $107 \pm 17$ & $>.05$ \\
\hline SBP at peak, $\mathrm{mmHg}$ & $131 \pm 22$ & $135 \pm 28$ & $>.05$ \\
\hline HR at rest, bpm & $81 \pm 18$ & $73 \pm 11$ & $<.05$ \\
\hline HR at peak, bpm & $116 \pm 23$ & $114 \pm 27$ & $>.05$ \\
\hline Peak of $\mathrm{VO}_{2}, \mathrm{ml} / \mathrm{kg} / \mathrm{min}$ & $13 \pm 4$ & $16 \pm 5$ & $<.05$ \\
\hline $\mathrm{VE} / \mathrm{VCO}_{2}$ slope & $45 \pm 16$ & $39 \pm 13$ & $<.05$ \\
\hline AT (seconds) & $153 \pm 82$ & $245 \pm 140$ & .01 \\
\hline AT $\mathrm{VO}_{2}$ & $10 \pm 2$ & $12 \pm 4$ & $<.05$ \\
\hline Peak CP, $\mathrm{mmHg} \cdot \mathrm{ml} / \mathrm{kg} / \mathrm{min}$ & $1805 \pm 744$ & $2225 \pm 1071$ & $<.01$ \\
\hline Maximal work load, Watts & $78 \pm 28$ & $86 \pm 26$ & $<.05$ \\
\hline Peak RER & $1,16 \pm 0,14$ & $1,11 \pm 0,07$ & $<.05$ \\
\hline Peak respiratory rate, /min & $30 \pm 8$ & $27 \pm 6$ & .01 \\
\hline Exercise duration, seconds & $406 \pm 175$ & $449 \pm 164$ & .01 \\
\hline NYHA class & $2,98 \pm 0,35$ & $1,88 \pm 0,4$ & $<.01$ \\
\hline Left ventricular end-systolic volume, $\mathrm{ml}$ & $157 \pm 69$ & $122 \pm 55$ & $<.01$ \\
\hline Left ventricular end-diastolic volume, $\mathrm{ml}$ & $205 \pm 79$ & $175 \pm 71$ & $<.01$ \\
\hline Mitral regurgitation, grade & $1.49 \pm 1$ & $1.12 \pm 0.9$ & $<.05$ \\
\hline QRS duration, ms & $154 \pm 35$ & & \\
\hline Beta-blocker, \% & 95 & & \\
\hline Diuretic, \% & 83 & & \\
\hline Angiotensin-converting enzym inhibitor, $\%$ & 85 & & \\
\hline
\end{tabular}

AT: anaerobic threshold, CP: circulatory power, HR: heart rate, Ms: milliseconds, NYHA: New York Heart Association, RER: respiratory exchange ratio, SBP: Systolic blood pressure, $\mathrm{VCO}_{2}$ : carbon dioxide production, $\mathrm{VE}$ : minute ventilation, $\mathrm{VO}_{2}$ : oxygen consumption, and yrs: years.

and mitral regurgitation were measured from $26 \pm 7$ to $27 \pm 8 \%$, from $137 \pm 0,11$ to $143 \pm 44 \mathrm{ml}$, and from $1,06 \pm$ 0,87 to $0,89 \pm 0,96$ (all $P>.05$ ).

27 patients (20 males, $58 \pm 14$ years) $(54 \%)$ were included in the responder subgroup. QRS duration at baseline was $162 \pm 29 \mathrm{~ms}$ and an ischaemic cause was found in $37 \%$.

NYHA symptom class was improved from $3 \pm 0,3$ to $1,78 \pm 0,42(P<.01)$. Peak HR was decreased from $85 \pm 21$ to $71 \pm 13 \mathrm{bpm}(P<.05)$. Peak $\mathrm{VO}_{2}, \mathrm{VE} / \mathrm{VCO}_{2}$ slope, RER, RR, exercise duration, peak circulatory power, peak workload, and peak respiratory rate were improved from $14 \pm 5$ to $16 \pm 5 \mathrm{ml} / \mathrm{kg} / \mathrm{min}(P<.05), 45 \pm 20$ to $38 \pm 15$ $(P<.01), 1,17 \pm 0,14$ to $1,11 \pm 0,07(P<.05), 31 \pm 11$ to $27 \pm 7 / \mathrm{min}(P<.05), 409 \pm 200$ to $460 \pm 193$ seconds $(P<.05), 1862 \pm 907$ to $2384 \pm 1235 \mathrm{mmHg} \cdot \mathrm{ml} / \mathrm{kg} / \mathrm{min}$ $(P=.01), 78 \pm 31$ to $89 \pm 33$ watts $(P<.01)$, and $31 \pm 10$ to $27 \pm 7 / \mathrm{min}(P<.05)$. Mean time to anaerobic threshold was improved from $133 \pm 5$ to $261 \pm 154$ seconds $(P=$ $.01)$. In addition, LV ejection fraction, telesystolic volume, and mitral regurgitation were improved from $22 \pm 8$ to $34 \pm 7 \%(P<.01), 173 \pm 81$ to $106 \pm 59 \mathrm{ml}(P<.01)$, and from grade $1,83 \pm 0,94$ to $1,3 \pm 0,76(P<.01)$, respectively.

\section{Discussion}

Reduction in the RER at peak (despite significant increase in exercise parameters) and improvement in the time to AT suggest a postponed muscular anaerobic metabolism during exercise 6 months after CRT, in particular in responder subgroup.

It was clearly confirmed that patients suffering from heart failure have muscular dysfunctions leading to an early anaerobic metabolism with a high production in carbon dioxide and a reduction in the oxygen consumption during exercise [15]. Skeletal muscle blood flow is limited in HF population probably due to a combination of low cardiac output and increased peripheral resistance as sympathetic tone overactivation and endothelial dysfunction leading to a reduction in muscular capillary density $[16,17]$. 
There is also evidence of a reduced percentage of slowtwitch-type 1 fibres with high oxidative enzyme content and an increased percentage of type $2 \mathrm{~B}$ fibres with high glycolytic capacity. In addition, previous trials confirmed a reduction in oxidative enzyme activity and in mitochondrial density and a phosphocreatine depletion leading to lactate accumulation. In response to metabolic distress in exercising muscle an exaggerated ergoreflex activation was found. This leads to excessive reflex sympathetic tone. Large previous trials confirmed an important ergoreflex overactivation in heart population correlated with exaggerated hyperventilation during exercise $[18,19]$. This model represents the "muscle hypothesis."

In our investigation, the ventilatory response evaluated by the linear regression slope relating the minute ventilation to the carbon dioxide production was significantly improved in particular in the responder subgroup as previously described [20]. In addition, heart rate at rest and peak respiratory rate were reduced after CRT implantation, in particular in the responder subgroup, suggesting a reduction in sympathetic tone. $95 \%$ of patients were treated with beta blockers before and after CRT without increase during followup. Heart rate reduction was previously described in a study by Wasserman et al. after CRT $(P<.001$ compared with baseline in the CRT-on group and $P<.01$ in the CRToff group) [21]. The effects of long-term beta blockade were demonstrated in heart failure population with a reduction in both ventilatory parameters (peak minute ventilation, peak carbon dioxide production, and respiration rate) and haemodynamic parameters (LV ejection fraction, heart rate and blood pressure) [22].

In addition, left ventricular volumes and ejection fraction were improved as well as the peak circulatory power. This simple haemodynamic noninvasive parameter was described to be a close approach of the "cardiac power" (production of both the cardiac output and the main blood pressure) for the evaluation of the cardiac pumping function. The peak $\mathrm{CP}$ was measured by the product of the peak $\mathrm{VO}_{2}$ and the SBP at peak of the exercise as described previously. It was confirmed that the peak CP is a strong prognostic marker in heart failure population. It incorporates arteriovenous difference, heart rate, stroke volume, and blood pressure responses at peak of the exercise [13]. Haemodynamic condition was clearly improved after CRT implantation, in particular for the responder subgroup.

In the nonresponder subgroup, no significant improvement was found in the haemodynamic parameters (LV ejection fraction, peak circulatory power) associated with a nonsignificant improvement in both exercise capacity and ventilatory response. In addition, in this population no significant decrease in peak RER and in time to AT was found, suggesting a persistent early muscular anaerobic metabolism.

We suggest that CRT leads to an improvement in peripheral blood flow by better haemodynamic conditions. It could lead to a shift from fast-twitch-type $2 \mathrm{~B}$ fibres to slowtwitch-type 1 fibres with an increase in oxidative metabolism, in mitochondrial density, and in oxygen consumption and in reduction in carbon dioxide production resulting in a postponed AT and in lower peak RER.

Muscular biopsies with mitochondrial density, oxidative enzymes, and capillary density measurements are needed to confirm our data. We could correlate biopsy results with ventilatory response and time to AT after CRT. The lack of histology support was the main limitation in our investigation. In addition, this prospective study was not a randomized control trial.

\section{Conclusion}

CRT improves haemodynamic condition and exercise capacity and reduces the ventilatory response during effort. In addition, CRT decreases the peak respiratory exchange ratio suggesting the possibility of increased efficiency of energy production in skeletal muscle with less anaerobic metabolism by a shift from a glycolytic to an oxidative metabolism. Link between the improvement in the peak RER, the ventilatory data, and the haemodynamic parameters suggests a reduction in the sympathetic tone explained by a decrease in the ergoreflex activity. But, large further studies are needed to confirm our data.

\section{References}

[1] W. T. Abraham, W. G. Fisher, A. L. Smith et al., "Cardiac resynchronization in chronic heart failure," The New England Journal of Medicine, vol. 346, no. 24, pp. 1845-1853, 2002.

[2] J. G. F. Cleland, J.-C. Daubert, E. Erdmann et al., "The effect of cardiac resynchronization on morbidity and mortality in heart failure," The New England Journal of Medicine, vol. 352, no. 15, pp. 1539-1549, 2005.

[3] T. De Marco, E. Wolfel, A. M. Feldman et al., "Impact of cardiac resynchronization therapy on exercise performance, functional capacity, and quality of life in systolic heart failure with QRS prolongation: COMPANION trial substudy," Journal of Cardiac Failure, vol. 14, no. 1, pp. 9-18, 2008.

[4] K. K. Witte and A. L. Clark, "Why does chronic heart failure cause breathlessness and fatigue?" Progress in Cardiovascular Diseases, vol. 49, no. 5, pp. 366-384, 2007.

[5] N. P. Buller and P. A. Poole-Wilson, "Mechanism of the increased ventilatory response to exercise in patients with chronic heart failure," British Heart Journal, vol. 63, no. 5, pp. 281-283, 1990.

[6] P. Ponikowski, D. P. Francis, M. F. Piepoli et al., "Enhanced ventilatory response to exercise in patients with chronic heart failure and preserved exercise tolerance: marker of abnormal cardiorespiratory reflex control and predictor of poor prognosis," Circulation, vol. 103, no. 7, pp. 967-972, 2001.

[7] M. F. Piepoli, A. C. Scott, A. Capucci, and A. J. S. Coats, "Skeletal muscle training in chronic heart failure," Acta Physiologica Scandinavica, vol. 171, no. 3, pp. 295-303, 2001.

[8] H. Drexler, U. Riede, T. Munzel, H. Konig, E. Funke, and H. Just, "Alterations of skeletal muscle in chronic heart failure," Circulation, vol. 85, no. 5, pp. 1751-1759, 1992.

[9] A. J. S. Coats, A. L. Clark, M. Piepoli, M. Volterrani, and P. A. Poole-Wilson, "Symptoms and quality of life in heart failure: the muscle hypothesis," British Heart Journal, vol. 72, no. 2, pp. S36-S39, 1994. 
[10] K. Dickstein, P. E. Vardas, A. Auricchio et al., "2010 Focused Update of ESC Guidelines on device therapy in heart failure: an update of the 2008 ESC Guidelines for the diagnosis and treatment of acute and chronic heart failure and the 2007 ESC Guidelines for cardiac and resynchronization therapydeveloped with the special contribution of the Heart Failure Association and the European Heart Rhythm Association," Europace, vol. 12, no. 11, pp. 1526-1536, 2010.

[11] A. Vahanian, H. Baumgartner, J. Bax et al., "Guidelines on the management of valvular heart disease: the task force on the management of valvular heart disease of the European society of cardiology," European Heart Journal, vol. 28, no. 2, pp. 230 268, 2007.

[12] R. Arena, J. Myers, S. S. Aslam, E. B. Varughese, and M. A. Peberdy, "Technical considerations related to the minute ventilation/carbon dioxide output slope in patients with heart failure," Chest, vol. 124, no. 2, pp. 720-727, 2003.

[13] A. Cohen-Solal, J. Y. Tabet, D. Logeart, P. Bourgoin, M. Tokmakova, and M. Dahan, "A non-invasively determined surrogate of cardiac power ('circulatory power') at peak exercise is a powerful prognostic factor in chronic heart failure," European Heart Journal, vol. 23, no. 10, pp. 806-814, 2002.

[14] C. M. Yu, W. T. Abraham, J. Bax et al., "Predictors of response to cardiac resynchronization therapy (PROSPECT)—study design," American Heart Journal, vol. 149, no. 4, pp. 600-605, 2005.

[15] B. Massie, M. Conway, R. Yonge et al., "Skeletal muscle metabolism in patients with congestive heart failure: relation to clinical severity and blood flow," Circulation, vol. 76, no. 5, pp. 1009-1019, 1987.

[16] D. Harrington and A. J. S. Coats, "Skeletal muscle abnormalities and evidence for their role in symptom generation in chronic heart failure," European Heart Journal, vol. 18, no. 12, pp. 1865-1872, 1997.

[17] A. Linke, N. Schoene, S. Gielen et al., "Endothelial dysfunction in patients with chronic heart failure: systemic effects of lowerlimb exercise training," Journal of the American College of Cardiology, vol. 37, no. 2, pp. 392-397, 2001.

[18] M. F. Piepoli, A. Kaczmarek, D. P. Francis et al., "Reduced peripheral skeletal muscle mass and abnormal reflex physiology in chronic heart failure," Circulation, vol. 114, no. 2, pp. 126-134, 2006.

[19] D. A. A. Grieve, A. L. Clark, G. P. McCann, and W. S. Hillis, "The ergoreflex in patients with chronic stable heart failure," International Journal of Cardiology, vol. 68, no. 2, pp. 157-164, 1999.

[20] J. Jaussaud, P. Blanc, N. Derval et al., "Ventilatory response and peak circulatory power: new functional markers of response after cardiac resynchronization therapy," Archives of Cardiovascular Diseases, vol. 103, no. 3, pp. 184-191, 2010.

[21] K. Wasserman, X. G. Sun, and J. E. Hansen, "Effect of biventricular pacing on the exercise pathophysiology of heart failure," Chest, vol. 132, no. 1, pp. 250-261, 2007.

[22] K. K. A. Witte, S. Thackray, N. P. Nikitin, J. G. F. Cleland, and A. L. Clark, "The effects of long-term $\beta$-blockade on the ventilatory responses to exercise in chronic heart failure," European Journal of Heart Failure, vol. 7, no. 4, pp. 612-617, 2005. 


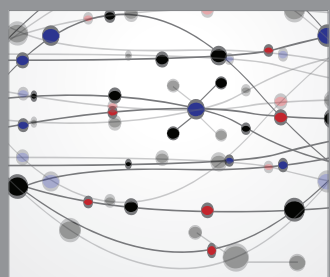

The Scientific World Journal
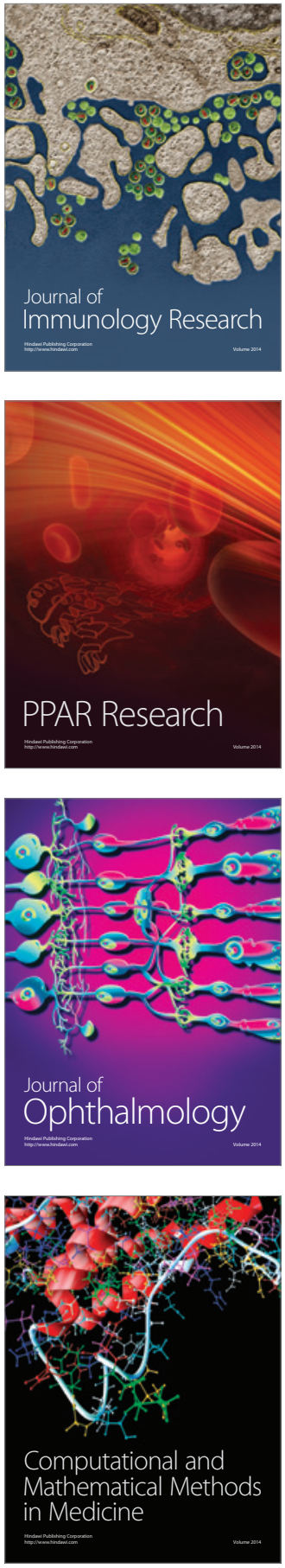

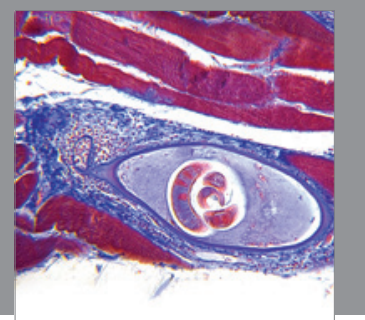

Gastroenterology

Research and Practice
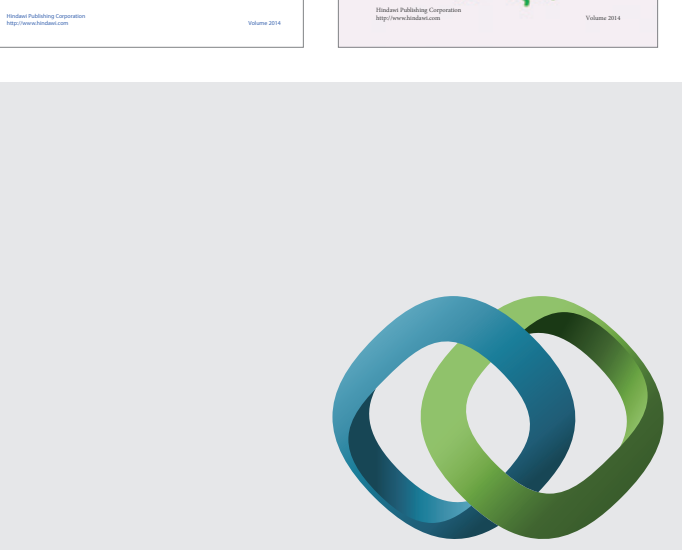

\section{Hindawi}

Submit your manuscripts at

http://www.hindawi.com
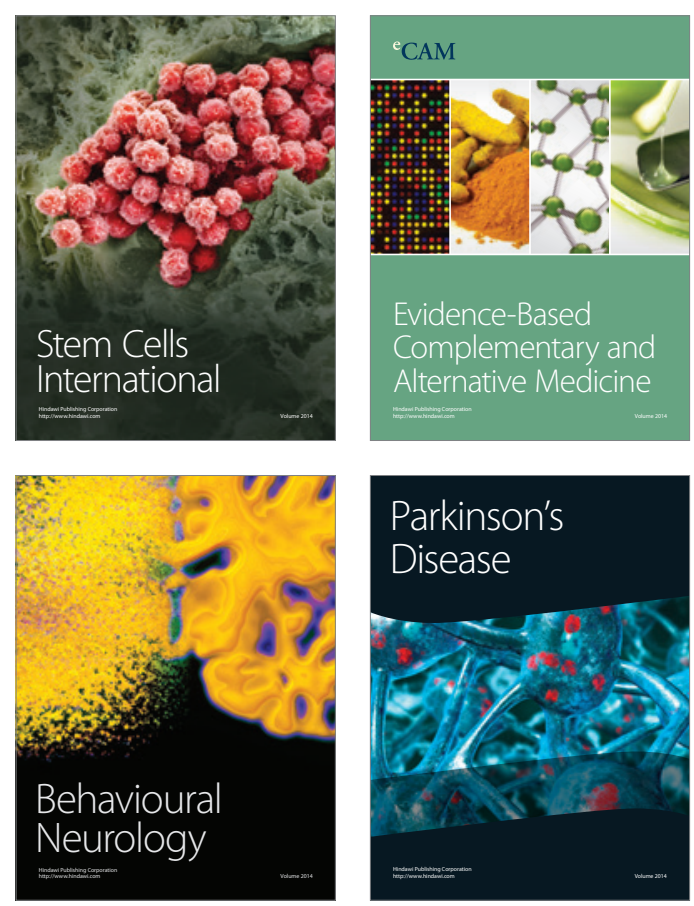

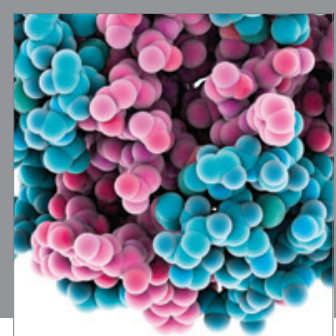

Journal of
Diabetes Research

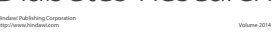

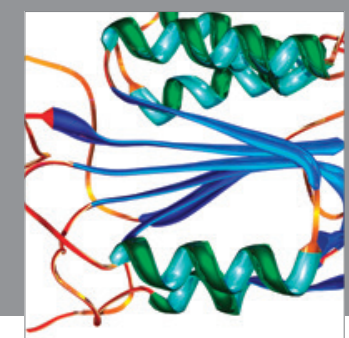

Disease Markers
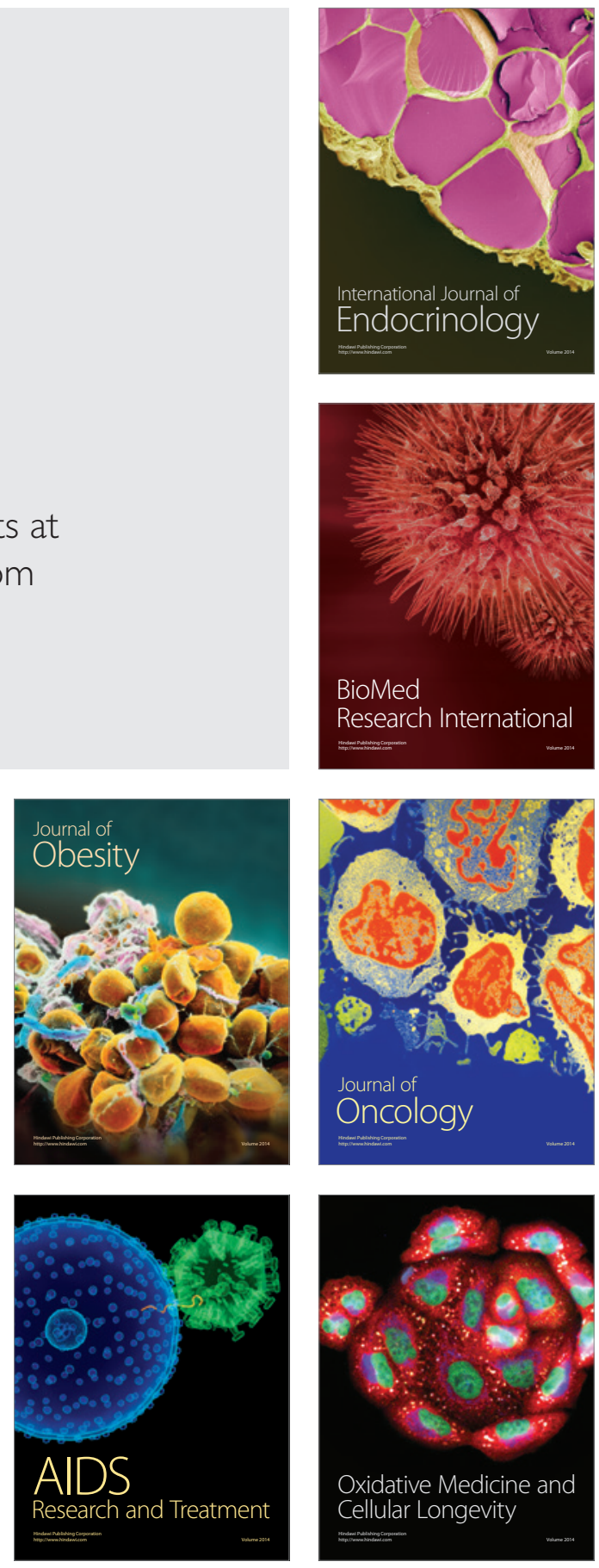